\title{
POLA DISTRIBUSI ABOVEGROUND BIOMASSA DAN STOKS KARBON TEGAKAN MANGROVE DI KAWASAN PESISIR SUNGAI PINYUH KABUPATEN MEMPAWAH
}

\author{
(Distribution pattern of Aboveground Biomass and Carbon Stocks of Mangrove Stand in \\ Coastal Sungai Pinyuh District Mempawah Regency)
}

\footnotetext{
Eko Subrata ${ }^{1)}$, Gusti Hardiansyah ${ }^{2)}$, Rafdinal ${ }^{3 *}$

${ }^{1}$ Magister Ilmu Kehutanan Fakultas Kehutanan Universitas Tanjungpura Jalan Imam Bonjol Pontianak ${ }^{2}$ Jurusan Ilmu Kehutanan, Fakultas Kehutanan Universitas Tanjungpura Jalan Imam Bonjol Pontianak

${ }^{3}$ Jurusan Biologi, Fakultas MIPA Universitas Tanjungpura Jalan Prof. Dr. H. Hadari Nawawi, Pontianak *e-mail: rafdinal@fmipa.untan.ac.id
}

\begin{abstract}
Mangrove ecosystem is one of the largest carbon storage on earth, has enormous environmental benefits in disaster mitigation, as well as a source of livelihood for coastal communities. The purpose of this research is to know the aboveground biomass distribution of mangrove forest stand and to know the potency of carbon stocks of the mangrove forest area of Mempawah Regency. The research was conducted from September to October 2017 in the mangrove forest of Sungai Pinyuh district of Mempawah Regency. Aboveground biomass measurements are performed in a $50 \times 50$ m measuring plot, data collection is performed by listing each stand with $\mathrm{dbh} \geq 5 \mathrm{~cm}$ and grouping it in diameter classes. Aboveground tree biomass estimation was performed using allometric equations and organic carbon stocks calculated by converting biomass by a conversion factor of 0.5. The results showed the biomass value ranged from 32.37 to 55.84 tons/ha with an average value of 40.28 tons/ha. The highest biomass is distributed in diameter class $15-25 \mathrm{~cm}$ with the percentage $23.10 \%$ and lowest in class diameter $>55 \mathrm{~cm}$ with a contribution equal to $13.39 \%$. Carbon stock in mangrove stand biomass ranged from 16.18-27.91 ton C / ha with an average value of 20.14 ton C / ha. Avicennia officinalis is an important type with the contribution of carbon reserves of $98.99 \%$.
\end{abstract}

Keywords: aboveground biomass, Carbon stock, mangrove forest, Mempawah Regency.

\begin{abstract}
Abstrak
Ekosistem mangrove merupakan salah satu gudang penyimpanan karbon terbesar di bumi, memiliki manfaat lingkungan yang besar dalam mitigasi bencana, serta sebagai sumber mata pencaharian masyarakat pesisir. Tujuan penelitian ini adalah untuk mengetahui distribusi aboveground biomass tegakan hutan mangrove dan mengetahui besarnya potensi cadangan karbon kawasan hutan mangrove Kabupaten Mempawah. Penelitian dilaksanakan dari bulan September hingga Oktober 2017 di hutan mangrove kecamatan Sungai Pinyuh Kabupaten Mempawah. Pengukuran biomassa atas permukaan (aboveground biomass) tegakan dilakukan di dalam petak ukur ukuran $50 \times 50 \mathrm{~m}$, pengumpulan data dilakukan dengan mendata tiap tegakan dengan $\mathrm{dbh} \geq 5 \mathrm{~cm}$ dan mengelompokkannya dalam kelas-kelas diameter. Pendugaan biomassa aboveground pohon (aboveground tree biomass) dilakukan dengan menggunakan persamaan allometrik dan stoks karbon organik dihitung dengan mengkonversikan biomassa dengan faktor konversi sebesar 0,5. Hasil menunjukkan nilai biomasa berkisar antara 32,3755,84 ton/ha dengan nilai rata-rata 40,28 ton/ha. Biomasa tertinggi terdistribusi pada kelas diameter $15-25 \mathrm{~cm}$ dengan persentase $23,10 \%$ dan terendah pada kelas diameter $>55 \mathrm{~cm}$ dengan kontribusi sebesar 13,39\%. Stoks karbon pada biomasa tegakan mangrove berkisar antara 16,18-27,91 ton C/ha dengan nilai rata-rata 20,14 ton C/ha. Avicennia officinalis merupakan jenis penting dengan kontribusi stoks karbon sebesar 98,99\%.
\end{abstract}

Kata kunci: Aboveground biomass, hutan mangrove, Kabupaten Mempawah, Stok karbon. 


\section{PENDAHULUAN}

Mitigasi perubahan iklim melalui restorasi dan perlindungan ekosistem pesisir merupakan salah satu program utama yang menjadi sasaran CIFOR. Ekosistem ini memiliki kapasitas penyimpanan karbon lima kali lebih besar dibandingkan dengan hutan tropis dataran tinggi (Murdiyarso et al., 2015) yang dikenal dengan karbon biru. Karbon biru pesisir merupakan bagian dari karbon biru termasuk pula karbon laut, yaitu karbon yang tersimpan dalam kolam karbon laut terbuka (CIFOR, 2017).

Ekosistem hutan mangrove umumnya dapat dijumpai di seluruh pulau di Indonesia, ekosistem ini berada di sepanjang pesisir daratan, jenis tumbuhan penyusunnya memiliki adaptasi yang sangat luas terhadap salinitas dan mampu bertahan pada kondisi tanah tergenang dan kurang stabil. Giri, et al. (2010) mengestimasi terdapat sekitar 3,1 juta hektar mangrove yang masih ada di Indonesia pada tahun dan merupakan yang terluas dari berbagai negara di dunia.

Ekosistem mangrove di Indonesia saat ini mengalami penurunan luasan dan kerusakan yang berarti. Kerusakan hutan mangrove disebabkan oleh konversi lahan yang sangat intensif pada tahun 1990-an menjadi pertambakan terutama di Jawa, Sumatera, Kalimantan dan Sulawesi dalam rangka memacu ekspor komoditas perikanan. Hal tersebut dapat dilihat dari perkembangan luas tambak di Indonesia dari sekitar total 3,48 juta hektar luasan hutan mangrove di Indonesia, 1,81 juta hektar diantaranya berada dalam kondisi rusak (KLHK, 2017).
Kabupaten Mempawah terletak di bagian pesisir provinsi Kalimantan Barat, memiliki potensi ekosistem mangrove seluas 739,30 Ha, terdistribusi di Kecamatan Mempawah Hilir, Mempawah Timur, Sungai Kunyit dan Sungai Pinyuh, namun dari tahun 1989 deteksi kerusakan diperkirakan seluas 250,88 Ha akibat abrasi dan alih guna lahan (Khairuddin et al., 2016). Penurunan kuantitas luasan ini juga berdampak terhadap kemampuan kolektif dari mangrove di Indonesia dalam fungsinya sebagai penyimpan karbon.

Tingkat kerusakan hutan mangrove sangat mempengaruhi nilai cadangan karbon pada vegetasi mangrove. Berdasarkan penelitian Azizah et al. (2013), nilai potensi biomassa dan cadangan karbon vegetasi mangrove di Segara Anakan, Cilacap, dapat berkurang lebih dari setengahnya pada vegetasi mangrove rusak dan kehilangan lebih kurang 90\% dalam dari potensi biomassa dan cadangan karbon vegetasi mangrove yang dalam keadaan baik.

Kawasan hutan mangrove Sungai Pinyuh merupakan salah satu kawasan hutan mangrove yang terdapat di Kabupaten Mempawah, secara kualitatif sebagian tergolong masih dalam keadaan baik. Kawasan ini menjadi salah satu sumber mata pencaharian sebagian penduduk yang memanfaatkan hasil hutan dan sebagai lokasi tambak ikan (BPS Kab. Mempawah, 2016). Selain itu kawasan ini juga berfungsi sebagai penahan interusi air laut, pengatur tata air, maupun sebagai penyedia oksigen dan penyerap karbon.

Penelitian bertujuan untuk menganalisa distribusi biomasa tegakan 
vegetasi mangrove serta mengestimasi potensi stoks karbon pada biomassa tegakan di kawasan hutan mangrove Kecamatan Sungai Pinyuh Kabupaten Mempawah.

\section{METODE PENELITIAN}

Penelitian ini dilaksanakan di kawasan
Mempawah pada tahun 2018. Waktu penelitian \pm 2 minggu efektif di lapangan. Identifikasi dan analisa data dilakukan di Laboratorium Silvikultur Fakultas Kehutanan UNTAN. Lokasi penelitian adalah Hutan Mangrove Sungai Pinyuh, Kabupaten Mempawah Kalimantan Barat (Gambar 1).

Pesisir Hutan Mangrove Kabupaten

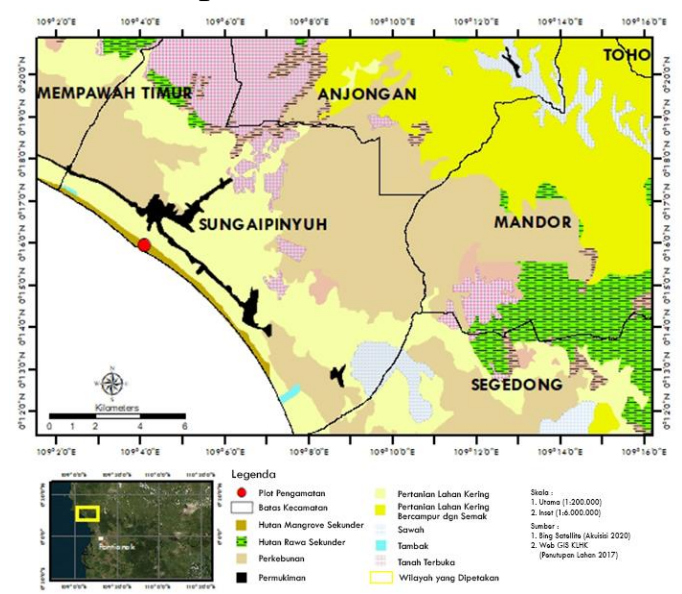

Gambar 1. Peta Lokasi Penelitian Hutan Mangrove Sungai Pinyuh, Kabupaten Mempawah (Study site: Mangrove Forest Sungai Pinyuh Mempawah Regency)

Alat dan bahan yang digunakan untuk pengukuran biomassa tumbuhan adalah pita ukur, meteran, tali rapia, kamera, plastik bening, GPS dan kalkulator.

\section{Pendugaan Biomasa}

Pengumpulan data aboveground biomass dilakukan secara non destruktif dengan mendata tiap tegakan yang memiliki $\mathrm{dbh} \geq 5 \mathrm{~cm}$ di dalam petak ukuran 50 x $50 \mathrm{~m}$ dan mengelompokkannya ke dalam kelas-kelas diameter (CFCRRDFORDA \& CIFOR, 2011; Hairiah et al., 2011). Pendugaan biomasa dilakukan dengan menggunakan persamaan allometrik (Komiyama et al., 2008).

\section{Estimasi Stoks Karbon}

Stoks karbon biomassa organik tersimpan dihitung dengan mengkonversikan biomassa pohon dan akar dalam bentuk karbon (Brown, 1997).

\section{Perhitungan Basal Area}

Pengukuran basal area tegakan mengacu pada perhitungan MuellerDombois dan Ellenberg (1974) dengan formula sebagai berikut:

$$
\text { Basal area }=(1 / 2 \mathrm{~d})^{2} \pi
$$

Dimana $\pi=3.14$

\section{Perhitugan Jumlah Biomassa di Atas Permukaan Pohon}

Pendugaan biomassa kayu dihitung berdasarkan nilai $d b h$ suatu tegakan dengan menggunakan persamaan allometrik (Komiyama et al., 2008).

$$
\mathrm{W}_{\text {top }}=0,251_{\rho \mathrm{D}} 2,46
$$

Dimana :

$\mathrm{W}_{\text {top }}$ : Biomassa atas permukaan (aboveground biomass) (kg/ha) 


$$
\begin{array}{ll}
\rho & : \text { Berat jenis kayu }\left(\mathrm{gram} / \mathrm{cm}^{3}\right) \\
\mathrm{D} & : \text { Diameter pohon }(\mathrm{cm})
\end{array}
$$

Data berat jenis kayu berdasarkan Global Wood Density Database (Zanne et al., 2009)

\section{Perhitungan Stoks Karbon Tersimpan pada Biomassa Pohon}

Stoks karbon tersimpan pada biomassa pohon dihitung dengan mengkonversikan biomassa dalam bentuk karbon. Biomassa tersebut dikali dengan faktor konversi sebesar 0,5 (Brown, 1997)

$$
\mathrm{C}=\mathrm{B} \times 0,5
$$

Dimana :

$$
\begin{aligned}
& \mathrm{C}=\text { Jumlah stok karbon (ton/ha) } \\
& \mathrm{B}=\text { Biomassa total tegakan (ton/ha) }
\end{aligned}
$$

HASIL DAN PEMBAHASAN

Hasil penelitian dari total 241 individu pohon yang ditemukan, terdapat 3 jenis mangrove sejati, yakni Avicennia officinalis ( $\mathrm{n}=236)$ famili Verbenaceae, Rhizophora sp. $\quad(\mathrm{n}=2) \quad$ famili Rhizophoraceae dan Bruguiera sp.(n=3) famili Rhizophoraceae. Kerapatan tegakan sebesar $964 \mathrm{ind} / \mathrm{ha}$ dan basal area tegakan sebesar 22,55 m²/ha.

\section{Basal Area Tegakan dan Distribusi Biomasa}

Gambar 2 menunjukkan dua grafik (garis dan batang) nilai aboveground biomass dan basal area pohon yang dikelompokkan berdasarkan kelas diameter di Hutan Mangrove Sungai Pinyuh Kabupaten Mempawah. Nilai AGB bekisar antara 32,37-55,84 ton/ha, AGB tertinggi terdistribusi pada kelas diameter 15-24,99 $\mathrm{cm}$ (dengan persentase nilai $23,10 \%$ ) dan AGB terendah terdistribusi pada kelas diameter $>55 \mathrm{~cm}$ (dengan persentase nilai 13,39\%). Total AGB dari seluruh kelas diameter sebesar 241,70 ton/ha. Basal area berkisar antara 2,11-5,92 $\mathrm{m}^{2} / \mathrm{ha}$, dengan basal area tertinggi pada kelas diameter 15$24,99 \mathrm{~cm}$ dan basal area terendah pada kelas diameter $>55 \mathrm{~cm}$.

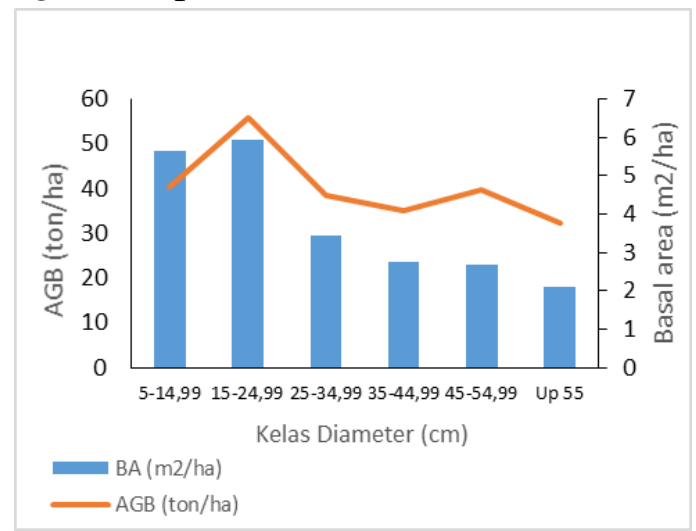

Gambar 2. Basal area dan biomasa atas permukaan Pohon Berdasarkan Kelas Diameter (Basal area and aboveground biomass based on diameter size class).

Nilai basal area ditentukan oleh besarnya diameter pohon, semakin besar diameter pohon, maka semakin besar nilai basal area pohon tersebut. Namun dalam skala kelompok vegetasi, nilai basal area tertinggi juga dipengaruhi oleh banyaknya individu pohon yang ditemukan. Pada lokasi Sungai Pinyuh kontribusi terbesar basal area terdapat pada kelas diameter kedua walaupun range diameternya lebih 
kecil dari kelas diameter diatasnya, hal ini dikarenakan jumlah individu yang lebih banyak ditemukan pada kelas diameter tersebut.

Distribusi biomasa tertinggi berada pada kelas diameter kedua, dengan nilai basal area tertinggi, trend peningkatan dan penurunan grafik AGB juga mengikuti grafik basal area. Dapat diasumsikan nilai basal area suatu komunitas (dalam skala kelas diameter yang ditentukan) berpengaruh postif terhadap nilai AGB yang terdistribusi pada komunitas tersebut, dikarenakan nilai basal area dianalisis melalui nilai-nilai diameter pohon yang ditemukan, demikian pula AGB.

\section{Stoks Karbon}

Berdasarkan total AGB, stoks karbon AGB kawasan Hutan Mangrove Desa Sungai Pinyuh berkisar antara 16,18-27,92 ton $\mathrm{C} /$ ha dengan total stoks karbon pada seluruh kelas diameter sebesar 120,85 ton C/ha. Berdasarkan jumlah tersebut, 23,10\% stoks karbon yang terdapat di lokasi ditentukan oleh tegakan dengan ukuran kelas diameter 15-24,99 cm dan kontribusi stoks karbon terendah terdapat pada kelas diameter $>50 \mathrm{~cm}$ dengan nilai 13,39\% (Tabel 1).

Stoks karbon AGB secara umum akan terkonsentrasi pada kelas diameter yang tertinggi dikarenakan semakin tinggi diameter pohon yang ditemukan, maka semakin tinggi nilai biomasa dan stoks karbonnya (Chave et al., 2014). Namun pada lokasi Sungai Pinyuh, stoks karbon AGB terbesar terdapat pada kelas diameter kedua, hal ini dikarenakan jumlah individu yang ditemukan pada kelas diameter tertinggi $(>55 \mathrm{~cm})$ sangat sedikit dengan nilai basal area paling rendah dari semua kelas diameter (Gambar 2).

Tabel 1. Potensi Stoks Karbon dan Persentasenya pada Masing-masing Kelas Diameter $(\geq 5 \mathrm{~cm}, \mathrm{dbh}$ ) (Carbon stocks potential and percentage in each diameter class)

\begin{tabular}{|c|c|c|}
\hline \multirow{2}{*}{ Diameter Size } & \multicolumn{2}{|c|}{ Carbon Storage } \\
\hline & Ton C/ha & Persentase (\%) \\
\hline $5-14,99 \mathrm{~cm}$ & 20,19 & 16,7 \\
\hline $15-24,99 \mathrm{~cm}$ & 27,92 & 23,1 \\
\hline $25-34,99 \mathrm{~cm}$ & 19,29 & 15,96 \\
\hline $35-44,99 \mathrm{~cm}$ & 17,45 & 14,44 \\
\hline $45-54,99 \mathrm{~cm}$ & 19,82 & 16,4 \\
\hline Up $55 \mathrm{~cm}$ & 16,19 & 13,39 \\
\hline Total & 120,85 & 100 \\
\hline
\end{tabular}

Berdasarkan grafik (Gambar 2) dan Tabel 1 distribusi biomassa atas permukaan dan cadangan karbon di lokasi penelitian masih didominasi oleh sapling dan pohon dengan diameter $<25$ $\mathrm{cm}$. Kondisi ini menunjukkan potensi besar peningkatan kemampuan penyimpanan serta penyerapan karbon per tahunnya di lokasi. Namun di sisi lain juga lokasi menjadi rentan kerusakan baik karena faktor alam ataupun penebangan untuk dijadikan bahan kayu oleh masyarakat. 
Tabel 2. Potensi Stoks Karbon dan Persentasenya pada Masing-masing Jenis yang Ditemukan (Carbon stocks potential and percentage in each species)

\begin{tabular}{lcc}
\hline \multirow{2}{*}{ Jenis } & \multicolumn{2}{c}{ Carbon Storage } \\
\cline { 2 - 3 } & Ton C/ha & Persentase (\%) \\
\hline Avicennia officinalis & 97,93 & 98,99 \\
Rhizophora sp. & 0,83 & 0,59 \\
Bruguiera sp. & 1,24 & 0,43 \\
\hline
\end{tabular}

Berdasarkan jenis yang ditemukan, jenis Avicennia officinalis memberikan kontribusi stoks karbon tertinggi dengan persentase $98,99 \%$ atau sebesar 119,63 ton C/ha. Kemudian jenis Rhizophora sp. dengan 0,59\% dan jenis Bruguiera sp. dengan $0,43 \%$ (Tabel 2).

Kontribusi cadangan karbon sejalan dengan nilai kerapatan jenis dari lokasi dengan nilai lebih dari $95 \%$ pada jenis $A$. officinalis. Jenis Avicennia merupakan jenis yang umum ditemukan pada zona I mangrove, memiliki adaptasi terhadap salinitas yang tinggi, jenis ini sangat penting sebagai barier yang berbatasan langsung dengan garis pantai pada ekosistem mangrove. Dengan kondisi hutan mangrove Sungai Pinyuh yang berbatasan sangat dekat dengan laut, jenis Avicennia sangat mendominasi jumlahnya dan menjadi kontributor terbesar stoks karbon pada lokasi.

Berdasarkan hasil estimasi, nilai stoks karbon AGB total Hutan Mangrove Sungai Pinyuh berkisar antara 16,18-27,92 ton $\mathrm{C} /$ ha dengan total stoks karbon sebesar 120,85 ton $\mathrm{C} /$ ha. Hasil ini lebih rendah dibandingkan dengan stoks karbon di Desa Peniti Kabupaten Mempawah dengan nilai 4,43-42,41 ton C/ha dan Hutan Mangrove Kubu Raya sebesar 282,7 ton C/ha (Rafdinal et al., 2019; CFCRRD-FORDA dan CIFOR, 2011). Namun lebih tinggi dibandingkan Hutan Mangrove Mikronesia sebesar 104,4 dan 169,2 ton C/ha (Kauffman et al., 2011), Hutan Mangrove Sofala Bay Mozambik (Sitoe et al., 2014) dengan nilai 28,31 ton $\mathrm{C} /$ ha dan Hutan Mangrove Kepulauan Riau (Mandari et al., 2016) dengan nilai 57,91 ton C/ha (Tabel $3)$.

Tabel 3. Perbandingan Stoks Karbon dengan Penelitian lain (Comparison of carbon stocks to other studies)

\begin{tabular}{lc}
\hline \multicolumn{1}{c}{ Tipe ekosistem hutan } & $\begin{array}{c}\text { Stock Carbon } \\
\text { (ton C/ha) }\end{array}$ \\
\hline Primary tropical forest Ulu Gadut & $235,57^{1}$ \\
Secondary tropical forest Ulu Gadut & $224,65^{1}$ \\
Mangrove Forest Peniti Villages, Mempawah & $4,43-42,41^{2}$ \\
Mangrove Forest Sofala Bay & $28,31^{3}$ \\
Mangrove Palau Site & $104,4^{4}$ \\
Mangrove Yap Site & $169,2^{4}$ \\
Mangrove Kubu Raya & $282,75^{5}$ \\
Mangrove Riau & $57,91^{6}$ \\
\hline
\end{tabular}

Referensi: 1) Rafdinal, et al., 2013, 2) Rafdinal et al., 2019, 3) Sitoe et al., 2014, 4) Kauffman et al., 2011, 5). CFCRRDFORDA and CIFOR, 2011, dan 6). Mandari et al., 2016 


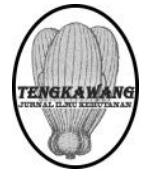

\section{KESIMPULAN}

Nilai biomasa tegakan hutan mangrove di kawasan pesisir Sungai Pinyuh berkisar antara 32,37-55,84 ton/ha dengan nilai rata-rata 40,28 ton/ha. Biomasa tertinggi terdistribusi pada kelas diameter $15-25 \mathrm{~cm}$ dengan persentase $23,10 \%$ dan terendah pada kelas diameter $>55 \mathrm{~cm}$ dengan kontribusi sebesar 13,39\%. Total AGB dari seluruh kelas diameter sebesar 241,70 ton/ha

Nilai stoks karbon pada biomasa tegakan mangrove berkisar antara 16,1827,91 ton $\mathrm{C} /$ ha dengan nilai rata-rata 20,14 ton $\mathrm{C} /$ ha dan total stoks karbon pada seluruh kelas diameter sebesar 120,85 ton C/ha.

Hutan Mangrove merupakan ekosistem penting yang memiliki kemampuan penyerapan karbon yang tinggi. Data penelitian menunjukkan pada lokasi Hutan Mangrove Kecamatan Sungai Pinyuh Kabupaten Mempawah memiliki stoks karbon yang cukup tinggi dibandingkan dengan beberapa jenis ekosistem hutan lainnya. Dengan peranannya yang penting, diharapkan hutan mangrove Kecamatan Sungai Pinyuh dapat tetap terjaga dari deforestasi dan alih guna lahan. Penelitan lebih lanjut dapat dilakukan pada lokasi penelitan dalam kajian dinamika perubahan cadangan karbon tiap tahunnya, untuk memonitor perkembangan resapan karbon yang terjadi di lokasi.

\section{DAFTAR PUSTAKA}

Azizah, M., Ardi, E. R. \& Sudiana, E. (2014). Analisis Stok Karbon Hutan Mangrove Pada Berbagai Tingkat Kerusakan di Segara Anakan Cilacap. Jurnal Sains Natural
Universitas Nusa Bangsa, Vol. 3(2), $161-172$.

BPS Kabupaten Mempawah. (2016). Kabupaten Mempawah Dalam Angka 2016. Diakses melalui laman https://mempawahkab.bps.go.id/

Brown, S. (1997). Estimating Biomass and Biomass Change of Tropical Forests: a Primer (FAO Forestry Paper134). FAO. United Nations, Rome

CFCRRD-FORDA \& CIFOR. (2011). Carbon Stock Assessment in Mangrove Ecosystem of Kubu Raya West Kalimantan. Final Report CFCRRD-FORDA. Bogor.

Chave, J., M. Rejou-Mechain, A. Burquez, E. Chidumayo, M. S. Colgan, W. B. Delitti, A. Duque, et al. 2014. "Improved Allometric Models to Estimate the Aboveground Biomass of Tropical Trees." Global Change Biology 20 (10): 3177-3190.

CIFOR. (2017). Penelitian Karbon Biru Untuk Pembangunan Berkelanjutan. Forest News. https://blog.cifor.org. diakses 7 Agustus 2017

Giri, C., E. Ochieng, L.L. Tieszen, Z. Zhu, A. Singh, T. Lovelnad, J. Masek and N. Duke. (2010). Stats and Distribution of Mangrove Forest of the World Using Earth Observation Satellite Data. Global Ecology and Biogeography, 1-6.

Hairiah, K., Dewi, S., Agus, F., Velarde, S., Ekadinata, A., Rahayu, S. \& van Noordwijk, M. (2011). Measuring Carbon Stocks Across Land Use Systems: A Manual. Bogor,Indonesia. World Agroforestry Centre (ICRAF), SEA Regional Office, 154 hal.

Kauffmann, J. B., Heider, C., Colem T. G., Dwire, K. A. \& Donato, D. C., 
(2011). Ecosystem Carbon Stocks of Micronesian Mangrove Forest. Wetlands, 31, 343-352.

Kementrian Lingkungan Hidup dan Kehutanan (KLHK). (2017). Kementrian Lingkungan Hidup dan Kehutanan Republik Indonesia. Retrieved September 25, 2020, from https://www.menlhk.go.id/site/singl e post $/ 282$

Khairuddin, B., Yulianda, F., Kusmana, C., \& Yonvitner. (2016). Degradation mangrove by using Landsat $5 \mathrm{TM}$ and Landsat 8 OLI. Procedia Environmental Sciences, 33, 460464.

Komiyama, A., Jin. E. O., Sasitorn P. (2008). Allometry, Biomass and Productivity of Mangrove Forest : A Review. Aquatic Botany, 89, 128137

Mandari, D. Z., Gunawan, H \& Isda, MN. (2016). Penaksiran Biomassa dan Karbon Tersimpan pada Ekosistem Hutan Mangrove di Kawasan Bandar Bakau Dumai. Jurnal Riau Biologia, 1(3), 17-23.

Mueller-Dombois \& Ellenberg, H. (1974). Aims and Methods of Vegetation Ecology. John Wiley and Sons. New York
Murdiyarso D., Purbopuspito J., Kauffman J. B. (2015). The potential of Indonesian mangrove forests for global climate change mitigation Nature Climate Change, 5(12), 1089-1092.

Rafdinal, Linda, R., Minsas, S. (2019). Pola Distribusi Aboveground Biomass Kawasan Hutan Mangrove Peniti Kalimantan Barat. Life Science 8 (1): 1-9.

Rafdinal. (2015). Dinamika Struktur Pohon Dan Cadangan Karbon Di Kawasan Hutan Hujan Tropik Ulu Gadut Sumatera Barat. Doctoral Thesis. Universitas Andalas. Padang

Sitoe, A. A., Mandlate, L. J. C. \& Guedes, B. S. (2014). Biomass and Carbon Stocks of Sofala Bay Mangrove Forest. Forest, 5, 1967-1981.

Zanne, A. E., Lopez-Gonzalez, G., Coomes, D. A., Ilic, J., Jansen, S., Lewis, S. L., Miller, R. B., Swenson, N. G., Wiemann, M. C. \& Chave, J. (2009). Global wood density database. diakses 16 November 2017.

http://hdl.handle.net/10255/dryad.23 $\underline{5}$ 